\title{
Enhanced Efficacy of Amodiaquine and Chlorpheniramine Combination over Amodiaquine Alone in the Treatment of Acute Uncomplicated Plasmodium falciparum Malaria in Children
}

\author{
C.O. Falade ${ }^{a, b}$ S.O. Michael ${ }^{a, b} \quad$ A.M.J. Oduola ${ }^{c}$ \\ a Departments of Pharmacology and Therapeutics, College of Medicine, University of Ibadan, and \\ ${ }^{b}$ Clinical Pharmacology Department, University College Hospital, Ibadan, Nigeria; \\ 'Special Program for Research and Training in Tropical Diseases, World Health Organization, Geneva, Switzerland
}

\section{Key Words}

Amodiaquine, efficacy $\cdot$ Chlorpheniramine $\cdot$ Falciparum malaria

\begin{abstract}
Objective: To evaluate the comparative efficacy of amodiaquine (AMQ) alone and the combination of $A M Q$ and chlorpheniramine $(C P)$ in the treatment of acute uncomplicated malaria in children. Subjects: Of the 110 children enrolled in the study, 103 with acute uncomplicated malaria, aged 6 months to 12 years, were evaluated using the 14-day modification of the WHO field test. The patients were randomized to 2 groups. Group 1 received supervised treatment with AMQ alone (10 mg AMQ base/kg daily for 3 days), while group 2 received supervised treatment with $A M Q$ (same dose as group 1) plus CP (AMQCP) for 7 days. Results: Both treatment regimens were well tolerated and no patient was withdrawn as a result of recurrent vomiting or drug-related adverse events. There was no significant difference in mean fever and parasite clearance times. The cure rates at day 7 were 90.2 versus $100 \%$ ( $\rho=0.027$ ) for AMQ versus AMQCP, while the day 14 cure rates were 85.9 versus $98.1 \%$ for AMQ versus AMQCP, respectively $(\rho=0.016)$. Conclusion: The combination of AMQ plus CP proved significantly more effective than AMQ alone in the treatment of acute uncomplicated falciparum malaria, most probably due to the enhancement of the antimalarial effect of AMQ by CP. The
\end{abstract}

combination of AMQCP could be a better alternative to AMQ alone as a companion drug in artemisinin-based combination therapies.

Copyright $\odot 2008$ S. Karger AG, Base

\section{Introduction}

Chloroquine, a 4-aminoquinoline, has been widely used in sub-Saharan Africa in the treatment of malaria because of its easy availability, affordability and good safety profile $[1,2]$. The rising prevalence of chloroquineresistant parasites has, however, compromised its efficacy [1-3], which had led to the change from chloroquine as first-line treatment to the more effective artemisininbased combination therapy (ACT) in Nigeria and many other African countries [3, 4].

However, some non-antimalarial drugs have been shown to reverse chloroquine resistance in Plasmodium falciparum in vitro and in animal models [5-8]. These include verapamil: a calcium channel antagonist; desipramine: a tricyclic antidepressant and chlorpheniramine (CP): a histamine type 1 receptor blocker. In vitro potentiation of the schizonticidal effect of some other aminoquinoline drugs, mondesethylamodiaquine, amopyroquine and bisquinoline WR 268,668 , by desipramine has also been reported $[9,10]$. Mondesethylamodiaquine is the main active metabolite of amodiaquine (AMQ), while

Dr. Catherine Olufunke Falade

Clinical Pharmacology Department

University College Hospital/University of Ibadan

Ibadan (Nigeria)

Tel.+234803326 4593, E-Mail fallady@skannet.com 
amopyroquine is another Mannich-base derivative of the 4-aminoquinolines.

The drug resistance reversal phenomenon was first reported in in vitro experiments with drug-resistant cancer cells [11]. Tsuruo et al. later showed that resistance reversal in vincristine- and adriamycin-resistant cancer cells by some calcium antagonists resulted from enhanced intracellular levels of these anticancer drugs by inhibition of their outward transport $[12,13]$. The high intracellular drug accumulation was directly related to the enhancement of the cytotoxicity of the antitumor agents [13]. CP, a histamine receptor type 1 blocker, has been validated clinically and shown to enhance the efficacy of chloroquine $[14,15]$. The clinical success of the $\mathrm{CP}$ resistance reversal phenomenon is possibly due to the enhanced exposure of parasites to chloroquine, as was observed with reversal of resistance in the treatment of drug-resistant cancer. In an in vivo study, Deloron et al. [16] reported increased chloroquine accumulation in the erythrocytes of $P$. yoelii-infected mice treated with $(+)$-amlodipine (a calcium channel inhibitor) plus chloroquine as compared with erythrocytes obtained from infected mice treated with chloroquine alone.

Although the high prevalence of chloroquine-resistant falciparum infection makes chloroquine an unsuitable component of ACT, AMQ, a Mannich-base derivative of 4-aminoquinoline, has remained highly efficacious $[17,18]$ and is a preferred companion drug for ACT $[19,20]$. AMQ in combination with artesunate is one of the preferred ACTs recommended by the World Health Organization (WHO) and has been adopted as the drug of choice for the treatment of acute uncomplicated malaria by some countries [20]. Lumefantrine, mefloquine and sulfadoxine-pyrimethamine are the other recommended companion drugs in ACTs [20].

$\mathrm{CP}$ was used extensively in Nigeria as an adjunct to chloroquine in the treatment of acute uncomplicated malaria for the prevention and treatment of chloroquine-induced pruritus for many years. In this study, we evaluated the efficacy of combined AMQ and CP compared to AMQ alone in the treatment of uncomplicated falciparum malaria in children living in a rural community in Nigeria.

\section{Subjects and Methods}

\section{Study Site and Study Population}

The study was conducted in Olode-Adetoun, a village in Southwestern Nigeria, between August 2000 and November 2001. Malaria transmission is intense and occurs all year round in the study area. In an open randomized study, 110 children aged 6 months to 12 years with clinical features of acute uncomplicated malaria were enrolled into the study. The children were enrolled if they had fever (temperature $>37.5^{\circ} \mathrm{C}$ ) or a history of fever in the $24 \mathrm{~h}$ preceding presentation, headache, vomiting, chills and rigors. Other inclusion criteria were confirmed asexual $P$. falciparum malaria with a parasite density of at least $1,000 / \mu$ l of blood, no history of antimalarial drug ingestion during the preceding 2 weeks and absence of any concomitant illnesses. The University of Ibadan/University College Hospital institutional review committee provided ethical clearance for the study. Informed consent to participate in the study was obtained from the parents or guardians of the enrolled children in addition to community consent from the village head and opinion leaders.

\section{Patient Treatment and Follow-Up}

The enrolled children were randomized into 2 treatment groups according to a pregenerated randomization table. The children randomized into group 1 (55) received AMQ (Camoquine $^{\mathrm{TM}}$, Pfizer) $10 \mathrm{mg}$ AMQ base per kilogram daily for 3 days, while those randomized into group 2 (55) received AMQ at the same dosage as group 1 plus CP (Piriton ${ }^{\mathrm{TM}}$, Evans). CP was administered at a starting dose of $6 \mathrm{mg}$ followed by $4 \mathrm{mg} 3$ times daily for those below the age of 5 years and $8 \mathrm{mg}$ starting dose followed by $6 \mathrm{mg} 3$ times daily for those 5 years of age or above (25/52). CP was administered for 7 days. Additional management included tepid sponging and administration of paracetamol at a dose of $10 \mathrm{mg} / \mathrm{kg}$ in patients with axillary temperature $\geq 38^{\circ} \mathrm{C}$. The children were seen daily between days 0 and 7 and on day 14 at the village clinic. At each visit, each study participant received a thorough physical examination, enquiries were made about adverse events and thick blood films were prepared for parasite identification and quantification. All doses of the study drugs were administered supervised by a nurse or village health worker. Patients (7: 3 AMQ, 4 AMQCP) who defaulted on follow-up appointment were visited at home by the village health workers and necessary procedures carried out. Blood films were air dried and then stained with fresh $10 \%$ Giemsa stain at pH 7.2 for 20 min. Stained blood smears were screened under a light microscope at $\times 1,000$ magnification. Asexual stages of $P$. falciparum were counted against a minimum of 200 white blood cells. Definitive parasite density was calculated using an assumed white cell count of $8,000 / \mathrm{mm}^{3}[21]$.

\section{Evaluation of Treatment Outcome}

The study design utilized the WHO 14-day modification for evaluating the efficacy of antimalarial drugs [22]. The 1973 WHO criteria were also used to assess response to treatment [23]. The cure rates on days 7 and 14 were defined as the proportion of patients cleared of asexual parasitemia within the specific time intervals after initiation of treatment without recrudescence. Parasite clearance time was defined as the time interval between initiation of drug therapy and clearance of patent parasitemia, which remained clear for the period of 14 days of follow-up, while fever clearance time was defined as the time taken from instituting therapy for temperature $>37.5^{\circ} \mathrm{C}$ to come down to $37.2^{\circ} \mathrm{C}$ and remain $<37.2^{\circ} \mathrm{C}$ for at least $72 \mathrm{~h}$. Associated adverse effects of therapy and treatment outcome (day 7 and 14 cure rates) were compared in the 2 groups. 
Table 1. Enrollment characteristics of children suffering from acute uncomplicated malaria treated with AMQ or AMQCP

\begin{tabular}{|c|c|c|c|}
\hline \multirow[t]{2}{*}{ Characteristic } & \multicolumn{2}{|l|}{ Drug treatment } & \multirow{2}{*}{$\begin{array}{l}\mathrm{p} \\
\text { value }\end{array}$} \\
\hline & AMQ & AMQCP & \\
\hline Completed follow-up & 51 & 52 & - \\
\hline Sex ratio $(M: F)$ & $15: 36$ & $18: 34$ & $0.72^{\mathrm{a}}$ \\
\hline \multicolumn{4}{|l|}{ Age, months } \\
\hline Mean $\pm \mathrm{SD}$ & $59.9 \pm 33.3$ & $68.5 \pm 29.9$ & \multirow[t]{2}{*}{$0.12^{\mathrm{b}}$} \\
\hline Range & $11-132$ & $10-120$ & \\
\hline \multicolumn{4}{|l|}{ Weight, kg } \\
\hline Mean \pm SD & $14.1 \pm 4.8$ & $15.7 \pm 4.7$ & \multirow[t]{2}{*}{$0.79^{\mathrm{b}}$} \\
\hline Range & $2-25$ & $8-27$ & \\
\hline \multicolumn{4}{|c|}{ Episodes of malaria in the preceding 6 months } \\
\hline No attack & $3(5.9)^{\circ}$ & $3(5.8)$ & \multirow[t]{3}{*}{$0.95^{\mathrm{a}}$} \\
\hline $1-2$ attacks & $38(74.5)$ & $39(75)$ & \\
\hline$\geq 3$ attacks & $10(19.6)$ & $10(19.2)$ & \\
\hline Liver enlargement & $32(62.8)$ & $37(71.2)$ & $0.36^{\mathrm{a}}$ \\
\hline Spleen enlargement & $29(56.9)$ & $32(61.5)$ & $0.63^{\mathrm{a}}$ \\
\hline \multicolumn{4}{|l|}{ Day 0 temperature, ${ }^{\circ} \mathrm{C}$} \\
\hline Mean $\pm S D$ & $38.1 \pm 1.1$ & $38.0 \pm 0.4$ & \multirow[t]{2}{*}{$0.69^{\mathrm{b}}$} \\
\hline Range & $36.5-40.1$ & $36.0-40.5$ & \\
\hline Temperature $<37.5^{\circ} \mathrm{C}$ & $16(31.4)$ & $14(26.9)$ & $0.62^{\mathrm{a}}$ \\
\hline \multicolumn{4}{|l|}{ Parasite density, $\mu l^{-1}$} \\
\hline Mean $\pm S D$ & $16,098 \pm 21,887$ & $16,405 \pm 25,315$ & \\
\hline Range & $1,004-118,400$ & $1,005-131,089$ & $0.69^{\mathrm{a}}$ \\
\hline
\end{tabular}

Figures in parentheses are percentages.

Tests of significance: ${ }^{\mathrm{a}} \chi^{2}$ test, ${ }^{\mathrm{b}} \mathrm{t}$ test.

\section{Statistical Analysis}

Data collected on the patients were analyzed using Epi-info version 6 statistical software (Centers for Disease Control and Prevention, Atlanta, Ga., USA). Proportions were compared by calculating $\chi^{2}$ with Yates proportion or Fisher's exact test. Normally distributed data were compared by Student's t test and Kruskal-Wallis test. Values are given in the text and tables as means \pm standard deviation and values of $\mathrm{p}<0.05$ were taken as significant.

\section{Results}

Of the 110 children enrolled in the study, 103 (95\%) completed the study and were evaluated. Seven children (4 AMQ, 3 AMQCP) were withdrawn from the study: 4 children ( 2 in each group) were withdrawn as a result of protocol violation (definitive parasite density $<1,000 / \mu \mathrm{l}$ ), while the remaining 3 were lost to follow-up between days 4 and 14, having traveled out of the village, and were excluded from the analysis. The 2 groups were similar in age, sex ratio, weight and initial parasite density. The enrollment characteristics of the study patients are shown in table 1.
Table 2. Treatment outcome among children suffering from acute uncomplicated malaria treated with AMQ alone or AMQCP

\begin{tabular}{llll}
\hline Characteristic & \multicolumn{2}{c}{ Drug treatment } & \multirow{2}{*}{ p value } \\
\cline { 2 - 3 } & AMQ & AMQCP & \\
\hline Completed follow-up & 51 & 52 & - \\
Sex ratio (M:F) & $15: 36$ & $18: 34$ & $0.72^{\mathrm{a}}$ \\
Fever clearance time, days & & & \\
$\quad$ Subjects & 34 & 35 & $0.75^{\mathrm{b}}$ \\
$\quad$ Mean \pm SD, days & $1.5 \pm 0.8$ & $1.4 \pm 0.7$ & \\
$\quad$ Range, days & $1-4$ & $1-4$ & \\
Parasite clearance time, days & & & \\
$\quad$ Mean \pm SD & $2.2 \pm 1.1$ & $2.0 \pm 1.1$ & $0.57^{\mathrm{b}}$ \\
$\quad$ Range & $1-5$ & $1-6$ & \\
Patent parasitemia on day 3 & $8(15.7)$ & $6(11.5)$ & $0.549^{\mathrm{a}}$ \\
Cure rates (S response) & & & \\
$\quad$ Day 7 & $46(90.2)$ & $52(100)$ & $0.027^{\mathrm{a}}$ \\
$\quad$ Day 14 & $43(85.9)$ & $51(98.1)$ & $0.016^{\mathrm{a}}$ \\
Day 14 response & & & \\
$\quad$ RI & $7(13.7)$ & $1(1.9)$ & \\
$\quad$ RII & $1(2)$ & 0 & $0.034^{\mathrm{a}}$ \\
$\quad$ RIII & 0 & 0 & \\
Adverse effects & & & \\
$\quad$ Vomiting & $4(7.8)$ & $4(7.7)$ & \\
$\quad$ Diarrhea & $2(3.9)$ & $1(1.9)$ & \\
Headache & $1(2.0)$ & $1(1.9)$ & $0.45^{\mathrm{a}}$ \\
Drowsiness & 0 & $3(5.8)$ & \\
$\quad$ Pruritus & 0 & $1(1.9)$ & \\
\hline
\end{tabular}

Figures in parentheses are percentages. $\mathrm{S}=$ Sensitive, clearance of parasitemia without recurrence; RI = mild resistance, parasitemia disappears but reappears within 7-14 days; RII = moderate resistance, parasitemia decreases but no complete clearance from the peripheral blood; RIII = severe resistance, no appreciable decrease or even increase in parasite density at $48 \mathrm{~h}$. Tests of significance: ${ }^{\mathrm{a}} \chi^{2}$ test, ${ }^{\mathrm{b}}$ t test.

\section{Fever and Parasite Clearance}

Details of treatment outcome are shown in table 2. Of the 51 patients from the group treated with AMQ 43 $(84.3 \%)$ and of the 52 patients of group 2 treated with AMQCP $46(88.5 \%)$ were free of patent parasitemia by day $3(\rho=0.539)$. The mean parasite clearance times were $2.23 \pm 1.07$ and $2.04 \pm 1.07$ days among patients treated with AMQ and AMQCP, respectively $(\rho=0.57)$, while the mean fever clearance times were $1.52 \pm 0.84$ and $1.35 \pm$ 0.67 days $(\rho=0.75)$ for AMQ and AMQCP, respectively. The day 7 cure rate among patients treated with AMQCP was $100 \%$, while that among those who received AMQ alone was $85.2 \%(\rho=0.027)$. The cure rate on day 14 was also higher among children treated with AMQCP compared with those who received AMQ alone (98.1 vs. $85.9 \%, \rho=0.016$ ). Children whose infection failed therapy 
(9; 8.7\%, 8 in the AMQ group and 1 in the AMQCP group) were treated with sulfadoxine-pyrimethamine (Fansidar ${ }^{\mathrm{TM}}$, Swipha). The response of the infection to sulfadoxine-pyrimethamine was prompt with all patients free of parasitemia by day 3 and remaining free of parasites and fever up to day 14 .

The adverse events recorded during the study were abdominal pain: 8 ; vomiting: 3 ; diarrhea: 3 ; headache: 2 ; drowsiness: 2 , and itching: 1 . All cases of vomiting occurred on day 0 . Two patients (1 in each group) vomited within $30 \mathrm{~min}$ of drug administration. The drug dose was repeated in these patients. There was no case of recurrent vomiting among the study participants. Pruritus subsided spontaneously in the only patient who reported this adverse event. Further history taking revealed that the child had no history of allergy to chloroquine, another 4-aminoquinoline. These adverse events were mild and similar in both treatment groups (table 2).

\section{Discussion}

The usefulness of chloroquine, which was the mainstay of treatment for malaria in Africa for many decades, has been severely eroded by the emergence of drug-resistant $P$. falciparum strains $[1,4,14,17]$. AMQ, a Mannichbase derivative of 4-aminoquinoline, has remained efficacious despite high levels of chloroquine resistance [17, 18]. As a result of this efficacy, AMQ has been approved as a companion drug to artesunate by the $\mathrm{WHO}$ and been adopted as a first-line antimalarial drug in many countries in Africa (Côte d'Ivoire, Ghana, Liberia and Sierra Leone) and Asia [20]. To encourage compliance, co-formulated preparations of ASAQ (Diasunate ${ }^{\mathrm{TM}}$, Emzor Pharmaceuticals) are now available. The day 14 cure rate of $85.9 \%$ recorded among patients who received AMQ alone in our study is remarkably superior to about $40 \%$ efficacy of chloroquine recorded in the study area previously $[1,4]$. This is consistent with reports by other workers $[17,18]$. Sowunmi et al. [17], working in the same environment, had earlier reported a day 14 cure rate of 98.1\% for AMQ, while Graupner et al. [18] reported a day 14 cure rate of $89.5 \%$ for AMQ from southeastern Nigeria. Also, Brasseur et al. [24], in a multicenter study spanning 4 African countries in central (Gabon and Cameroon) and west Africa (Burkina Faso and Senegal), reported day 14 cure rates of 100, 97, 96, 87 and 61\% in Cameroon, Dakar in Senegal, Burkina Faso, Gabon, and Morup in Senegal respectively. However, the occurrence of cross-resistance between chloroquine and AMQ $[9,25]$ is well rec- ognized and this may greatly limit its efficacy against chloroquine-resistant strains of $P$. falciparum. This may, in turn, reduce the therapeutically useful life of AMQcontaining ACTs.

The results of this study show that the combination of AMQ and CP has a higher efficacy than AMQ alone (table 2). The day 7 and 14 cure rates of 100 and $98.1 \%$ among children who were treated with AMQ plus CP were significantly higher than among those treated with AMQ alone. One of the 8 patients whose infection failed to respond to AMQ alone had an RII pattern of response, while the other 7 had an RI pattern of response. The only patient whose infection failed to respond to the combined therapy of AMQ and CP on day 14 exhibited an RI response. Malaria transmission is intense in the study area and some of the treatment failures seen in this study could have been reinfections despite the relatively short period of 14 days of follow-up. It is also noteworthy that fewer patients treated with AMQ and CP combination therapy had patent parasitemia at day 3 compared to those treated with AMQ alone. However, this difference was not statistically significant.

The adverse events recorded during this study were few and mild and no study participant was withdrawn as a result of adverse events. This good safety profile for AMQ and the combination of AMQ and CP obtained in our study is consistent with the results of previous workers in various parts of Africa [17, 18, 24]. The reported adverse events were also few in the study by Brasseur et al. [24], mainly being limited to pruritus and nausea. A major limitation of this report is that the study was completed in the year 2001 and may not represent the drug efficacy rates at the present time. Also, the protocol for evaluating the efficacy of antimalaria drugs has been extended to 28 days, with genotyping now available for distinguishing recrudescence from reinfection [26]. The efficacy at day 28 would most probably be lower than the day 14 efficacy reported here.

\section{Conclusion}

The findings of this study show that AMQ was effective in the treatment of acute uncomplicated malaria and that the antimalarial efficacy of AMQ was enhanced by addition of CP. The combination of AMQ plus CP was also safe and efficacious in the treatment of falciparum malaria in an area of established chloroquine resistance. Despite the limitations of this study the enhancement of the antimalarial effect of AMQ by CP would prolong the 
clinically useful lifespan of AMQ. It is worthwhile investigating the benefit or otherwise of adding CP to AMQ when used as the companion drug of ACTs. The enhancement of AMQ efficacy may thus be put to positive use in this application.

\section{Acknowledgments}

This study received financial support from WHO/TDR/RCS grant ID 970678. A.M.J.O. is the recipient of the grant. We are grateful to all our study participants and their parents/guardians. We thank our research staff Mrs. Rashedat Adedoja, Mrs. Fatimah AbduSalam, Mrs. Lanre Ogundipe and the village health workers.

\section{References}

$>1$ Falade CO, Salako LA, Sowunmi A, Oduola AM, Larcier P: Comparative efficacy of halofantrine, chloroquine and sulfadoxine-pyrimethamine for treatment of acute uncomplicated falciparum malaria in Nigerian children. Trans R Soc Trop Med Hyg 1997;91: 58-62.

2 Trape JF: The public health impact of chloroquine resistance in Africa. Am J Trop Med Hyg 2001;65:12-17.

3 WHO: Antimalarial Drug Combination Therapy: Report of a WHO Technical Consultation. WHO/CDS/RBM/2001.35. Geneva, WHO, 2001.

4 Federal Ministry of Health, National Malaria and Vector Control Division: National Malaria Treatment Policy. Abuja, Federal Ministry of Health, 2004.

5 Martin SK, Oduola AM, Milhous WK: Reversal of chloroquine resistance in Plasmodium falciparum by verapamil. Science 1987 ; 235:899-901.

6 Bitonti AJ, Sjoendoma A, McCann PP, Kyle DE, Oduola AMJ, Rossan RN, Mihous WK, Davidson DE Jr: Reversal of chloroquine resistance in malaria parasite Plasmodium falciparum by desipramine. Science 1988;242: 1301-1303.

7 Omitowoju GO, Ogundahunsi OAT, Milhous WK, Gerena L, Sowunmi A, Schuster BG, Oduola AMJ: Chlorpheniramine: a resistance reversing agent with potential clinical application (abstract 379). Am J Trop Med Hyg Annu Meet, Atlanta, November $1-4,1992$.

$>8$ Kyle DE, Milhous WK, Rossan RN: Reversal of Plasmodium falciparum in Aotus monkeys. Am J Trop Med Hyg 1993;48:126-133.

-9 Basco LK, Le Bras J: Potentiation of mondesethylamodiaquine and amopyroquine with desipramine against Plasmodium falciparum in vitro. Trans R Soc Trop Med Hyg 1991;85: 447-448.

- 10 Basco LK, Anderson SL, Milhous WK, Le Bras J, Vennerstrom JL: In vitro activity of bisquinoline WR 268,668 against African clones and isolates of Plasmodium falciparum. Am J Trop Med Hyg 1994;50:200205.
11 Tsuruo T, Iida H, Tsukagoshi S, Sakurai Y: Overcoming of vincristine resistance in P388 leukemia in vivo and in vitro through enhanced cytotoxicity of vincristine and vinblastine by verapamil. Cancer Res 1981; 41:1967-1972.

12 Yusa K, Tsuruo T: Reversal mechanism of multidrug resistance by verapamil: direct binding of verapamil to P-glycoprotein on specific sites and transport of verapamil outward across the plasma membrane of K562/ ADM cells. Cancer Res 1989;49:5002-5006.

13 Tsuruo T, Iida H, Tsukagoshi S, Sakurai Y: Increased accumulation of vincristine and adriamycin in drug-resistant p388 tumor cells following incubation with calcium antagonists and calmodulin inhibitors. Cancer Res 1982;42:4730-4733.

14 Sowunmi A, Oduola AM, Ogundahunsi OA, Falade CO, Gbotosho GO, Salako LA: Enhanced efficacy of chloroquine-chlorpheniramine combination in acute uncomplicated falciparum malaria in children. Trans R Soc Trop Med Hyg 1997;91:63-67.

15 Sowunmi A, Fehintola FA, Ogundahunsi OAT, Oduola AMJ: Comparative efficacy of chloroquine plus chlorpheniramine and halofantrine in acute uncomplicated malaria in Nigerian children. Trans R Soc Trop Med Hyg 1998;92:441-445.

16 Deloron P, Basco LK, Dubois B, Gaudin C, Clavier F, Le Bras J, Verider F: In vitro and in vivo potentiation of chloroquine against malaria parasites by an enatiomer of amlodipine. Antimicrob agents chemother 1991;35: 1338-1342.

17 Sowunmi A, Ayede AI, Falade AG, Ndikum VN, Sowunmi CO, Adedeji AA, Falade CO, Happi TC, Oduola AM: Randomized comparison of chloroquine and amodiaquine in acute uncomplicated malaria. Ann Trop Med Parasitol 2001;96:409-418.

18 Graupner J, Göbels K, Groubusch MP, Lund A, Richter J, Häussinger D: Efficacy of amodiaquine in uncomplicated falciparum malaria in Nigeria in an area with high-level resistance to chloroquine and sulfadoxinepyrimethamine. Parasitol Res 2005;96:162165.
19 Adjuik M, Agamey P, Babikar A, Borrmann S, Brasseur P, Cisse M, Cobelens F, Diallo S, Fauche JF, Garner P, Gikunda S, Kremsner PG, Krishna S, Lell B, Loolpapit M, Matsiegu PB, Missinou MA, Mwanza J, Ntoumi F, Olliaro P, Osimbo P, Rezbach P, Some E, Taylor WR: Amodiaquine-artesunate versus amodiaquine for uncomplicated Plasmodium malaria in African children: a randomized multicentre trial. Lancet 2002;359:13651372.

20 WHO: Facts on ACTs (Artemisinin-Based Combination Therapies). January 2006 update. http://www.rbm.who.int/cmc_upload/0/000/015/364/RBMInfosheet_9.htm.

21 Trape JF: Rapid evaluation of malaria parasite density and standardization of thick smear for epidemiological investigation. Trans R Soc Trop Med Hyg 1985;79:181184

22 World Health Organization: Assessment of Therapeutic Efficacy of Antimalarial Drugs for Uncomplicated Falciparum Malaria in Areas of Intense Transmission. WHO/Mal/ 96.1077. Geneva, WHO, 1996.

23 World Health Organization: Chemotherapy of Malaria and Resistance to Antimalarials. WHO Tech Rep Ser No 529. Geneva, WHO, 1973.

24 Brasseur P, Guiguenide R, Diallo S, Guiyedi V, Kombila M, Ringwald P, Olliaro P: Amodiaquine remains effective for treating uncomplicated malaria in Central and East Africa. Trans R Soc Trop Med Hyg 1999;95: 645-650.

25 Basco LK: Inefficacy of amodiaquine against chloroquine-resistant malaria. Lancet 1991; 338:1460.

26 World Health Organization: Assessment and Monitoring of Antimalarial Drug Efficacy for the Treatment of Uncomplicated Falciparum Malaria. WHO/HTM/RBM/ 2003.50. Geneva, WHO, 2003. 